\title{
Features associated with melanoma metastasis in Latvia
}

\author{
DACE PJANOVA $^{1 *}$, DACE RUKLISA ${ }^{2 *}$, ELZA KREGERE ${ }^{1}$, \\ KRISTINE AZARJANA ${ }^{3}$, AIJA OZOLA ${ }^{1}$ and INGRIDA CEMA ${ }^{4,5}$ \\ ${ }^{1}$ Cancer Cell Biology and Melanoma Research Group, Latvian Biomedical Research and Study Centre, Riga LV-1067, \\ Latvia; ${ }^{2}$ Newnham College, University of Cambridge, Cambridge CB3 9DF, UK; ${ }^{3}$ Post-diploma Education Institute, \\ University of Latvia, Riga LV-1586; ${ }^{4}$ Department of Oral Pathology, Riga Stradiňs University, Riga LV-1007; \\ ${ }^{5}$ Surgical Oncology Clinic, Riga East University Hospital Latvian Oncology Centre, Riga LV-1079, Latvia
}

Received January 21, 2020; Accepted June 15, 2020

DOI: $10.3892 / 01.2020 .11978$

\begin{abstract}
Cutaneous melanoma (CM) is the most aggressive form of skin cancer, exhibits an increasing incidence worldwide and has a high potential to develop metastasis. The current study aimed to identify a set of parameters that may aid in predicting the probability and timing of the onset of $\mathrm{CM}$ metastasis. A retrospective analysis was performed using the archive data of 2,026 patients with CM that were treated at the Riga East University Hospital Latvian Oncology Centre, which is the largest oncological hospital in the country, between 1998 and 2015. A case-control study design was employed, where patients with metastasis $(n=278)$ were used as the cases and patients without metastasis were used as the controls. The present study examined the associations between metastasis and potential risk factors and constructed multivariate models of features that predicted metastasis using stepwise regression. Time until metastasis was analyzed using negative binomial regression models. The results of the present study indicated an increase in the number of melanomas that developed metastases during 1998-2015. Tumor Breslow thickness was demonstrated to be significantly larger in patients with metastasis compared with those without $(\mathrm{P}=0.012)$. The presence of ulceration significantly increased the risk of metastases [odds ratio (OR), 1.66; 95\% CI, 1.07-2.59; $\mathrm{P}=0.033$ ]. The absence of pigment in melanoma tissues was indicated to lead to a greater likelihood of metastasis (OR, 2.14; 95\% CI, 1.10-4.19; $\mathrm{P}=0.035)$. Shorter times from diagnosis until the
\end{abstract}

Correspondence to: Dr Dace Pjanova, Cancer Cell Biology and Melanoma Research Group, Latvian Biomedical Research and Study Centre, 1 Ratsupites Street, Riga LV-1067, Latvia

E-mail: dace@biomed.lu.lv

*Contributed equally

Abbreviations: CM, cutaneous melanoma; REUHLOC, the Riga East University Hospital Latvian Oncology Centre; HR, hazard ratio; IRR, incident rate ratio; $\mathrm{BMI}$, body mass index

Key words: melanoma, metastasis, prognosis, survival, Breslow thickness, ulceration, pigment onset of metastases were observed in older patients (incident rate ratio (IRR), $6.85 ; 95 \% \mathrm{CI}, 2.43-19.30 ; \mathrm{P}=2.78 \times 10^{-4}$ ), and a borderline significant association was observed in those with ulcerated tumors (IRR, 1.33; 95\% CI, 0.98-1.80; $\mathrm{P}=0.064$ ). Therefore, the main features associated with the development of melanoma metastasis in Latvia were indicated to be tumor ulceration, absence of pigment and Breslow thickness.

\section{Introduction}

Cutaneous melanoma (CM) is one of the most aggressive types of skin cancer and mainly affects the Caucasian population (1). Epidemiological data collected across the world demonstrate a steady increase in the incidence of melanoma in recent decades. In the USA, the incidence of CM in the Caucasian subpopulation increased from 20.9 in 1996 to 31.5 in 2017 (2) (the incidence rates reported are per 100,000 individuals per year). In Germany, the incidence of CM grew from 10.3 in 1976 to 13.3 in 2003 (3). In Finland, from 1953-2003 the incidence of CM changed from 1.5 to 12.8 (4). The incidence of melanoma in Latvia has increased from 5.1 new melanoma cases per 100,000 inhabitants in 1998 to 7.8 in 2008 (5). Although this increase is mainly attributed to the early detection of the disease, the number of patients diagnosed with advanced melanoma and with cancer exhibiting metastatic potential is also growing worldwide $(6,7)$, with $\sim 30 \%$ of patients with primary melanoma developing metastasis $(8,9)$. Metastatic melanoma has a poor prognosis, with the median survival time ranging between 8 and 18 months following diagnosis depending on the tumor stage $(10,11)$. The efficacy of the treatment of metastatic melanoma in recent years has increased following the successful application of small molecular inhibitors that target specific oncogenic mutations, for example those within the $B R A F$ gene $(12,13)$. Studies have also suggested that the development of immunotherapy with checkpoint inhibitors, which involves using monoclonal antibodies to cytotoxic $\mathrm{T}$ lymphocyte antigen- 4 and programmed death-1 receptor/ligand, may aid in the treatment of this disease (14-16). However, the efficacy of these treatments is limited by the development of resistance to targeted therapy $(12,13)$. Furthermore, durable response to immunotherapy is restricted only to a subset of patients (14-16).

The previously reported risk factors for a poor outcome of melanoma include high Breslow thickness, ulceration, high 
mitotic rate, high levels of lactate dehydrogenase, lymphovascular invasion and microscopic and clinical satellites (17-22). The formation of metastasis has also been associated with old age, the presence of a number of primary tumor localizations and a history of skin cancer or other types of cancer (23-25). In the aforementioned studies, the majority of melanomas were thin and rarely exceeded a Breslow thickness of $4.0 \mathrm{~mm}$; by contrast, melanomas in Latvia have been reported to exhibit a median thickness of $6.0 \mathrm{~mm}$ (5). This may be due to the delays in seeking medical assistance, which allows for a unique patient cohort where patients with metastasis are well represented and the tumors exhibit diverse features. This cohort presents opportunities for identifying additional features that may be associated with melanoma metastasis. In addition, to the best of our knowledge, the current study is the first systematic study of metastatic melanoma in the Latvian population. The aim of the present study was to analyze patient data and tumor characteristics in order to identify a set of parameters that may aid in predicting the probability and timing of the onset of CM metastasis.

\section{Materials and methods}

Design and data sources. In the present retrospectivecase-control analysis, patients with metastasis (T stages IIIA-IV) served as the cases (the first occurrence of metastasis for the primary tumor was considered), whereas patients with melanoma who did not develop metastasis during the study period were used as the controls (T stages IA-IIC). Staging was determined according to the guidelines by the American Joint Committee of Cancer, 8th Edition (11). Patient inclusion criteria were: Histologically confirmed melanoma with metastasis (corresponding to the T stage groups IIIA-IV) for cases and histologically confirmed melanoma without metastasis (corresponding to the $\mathrm{T}$ stage groups IA-IIC) for controls. Patients with multiple primary melanomas where it was not possible to identify a single original melanoma were excluded from the study. The cases and controls were selected from a cohort of 2,026 patients with CM that were treated at the Riga East University Hospital Latvian Oncology Centre (REUHLOC), which is the largest oncological hospital in Latvia, between January 1998 and December 2015. Of all melanoma cases in Latvia, $\sim 80 \%$ were referred to REUHLOC during this time period. Metastasis was defined as in-transit metastasis (manifested before regional lymph nodes), metastasis with regional lymph node involvement or distant metastasis. A total of 647 patients in the cohort developed metastasis. Individuals for whom metastasis was detected at the time of the diagnosis of primary tumor or $<6$ months after the initial diagnosis were excluded from the analysis due to a high probability of exhibiting metastasis in a subclinical form at the time of the diagnosis. Following this exclusion, 309 cases remained and were used for subsequent analysis. For each case, one control initially diagnosed in the same year was selected; the chosen control patient was required to have been followed up at least until the time when metastasis had been detected in the case patient and not to have died prior to the diagnosis of metastases. Age and sex were also considered when matching a case patient with a control: Patients were divided into age groups spanning 20 years each, and each patient was matched with a control from the same age group and of the same sex. When several controls were available, one control was selected at random. A total of 278 cases were successfully matched using all the criteria, and the total number of individuals included in the case-control study was 556. The variables examined for an association with the risk of developing metastasis were body mass index (BMI) and tumor characteristics, including CM subtype, predominant cell type in the lesion, Breslow thickness, presence of ulceration, pigment and anatomic localization of the tumor. Tumor localizations were grouped into the following regions: Head and neck, limbs, hands and feet, and trunk. Among the CM subtypes, superficial spreading melanoma, nodular melanoma and lentigo malignant melanoma were distinguished. Of all predominant cell types, epithelial, spindle and mixed cell types were discerned.

Statistical analysis. The associations between potential risk factors (categorical features) and the probability of developing metastasis were assessed using a Pearson's $\chi^{2}$ test. The distributions of risk factors for male and female patients were compared in the same way for case and control groups. If the number of patients in one of the subgroups was small, a Fisher's exact test was used. If the association with a factor was significant and the factor had $\geq 3$ discrete categories, pairwise comparisons between the categories were performed using Fisher's exact test. The differences in Breslow thickness, age and BMI (continuous features) were also assessed using the non-parametric Mann-Whitney test. For continuous features the mean \pm standard deviation (mean $\pm S D$ ) was reported. Both Pearson's $\chi^{2}$ tests and Fisher's exact tests were carried out using $\mathrm{R}$ software version 3.6.3. (functions 'chisq.test' and 'fisher. test' were used, respectively) (26). Odds ratios were calculated using the R function 'oddsratio'. Mann-Whitney test P-values were obtained by the 'wilcox.test' in $\mathrm{R} . \mathrm{P}<0.05$ was considered to indicate a statistically significant difference.

Multivariate models were constructed using several risk factors associated with the presence or absence of metastases. Logistic regression models were used in all multivariate analyses. Multivariate models were constructed using stepwise regression, where the candidate variables were Breslow thickness, BMI (both analyzed as continuous variables), ulceration, pigment and tumor localization. Multivariate models included patients with no missing data for the analyzed variables $(n=272 ; 136$ cases and controls matched for sex and age). $\mathrm{CM}$ subtype and predominant cell type in the lesion were not included in the present analysis due to insignificant P-values in the univariate analysis (Pearson's $\chi^{2}$ test or Fisher's exact test P-values were regarded as appropriate for the number of observations; the test that involved all categories of a feature was referred to) and missing observations. Models were built using the function 'stepAIC' from the R package 'MASS', starting with a model without any factors (27).

Within the group of patients with metastasis $(n=309)$, time from initial diagnosis until the diagnosis of metastasis was compared for a variety of subgroups. The features that were previously considered for the inclusion in the multivariate models were analyzed. A negative binomial regression model was fitted for each risk factor. The R function 'glm.nb' was used for computations.

Patient survival was assessed using the Cox proportional hazards model. The significance of the association between 

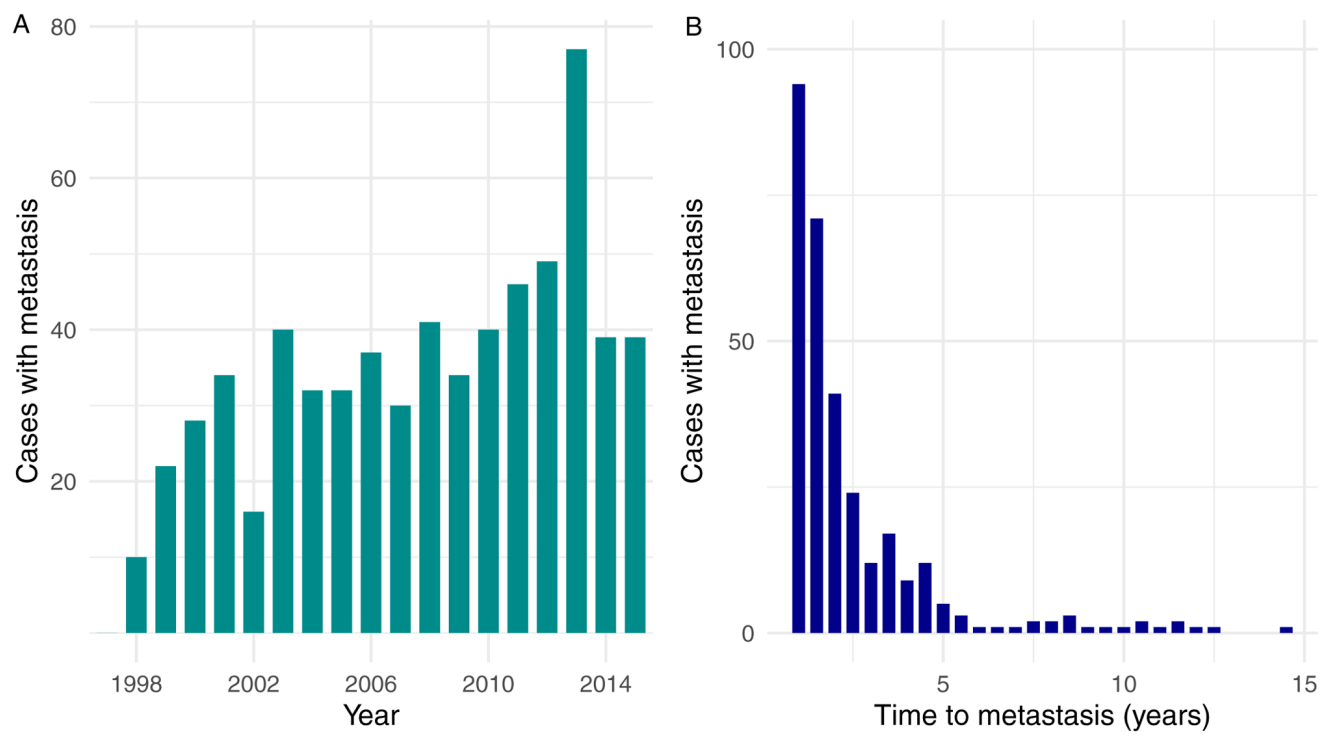

Figure 1. Occurrence of metastasis in the cohort. (A) The number of newly diagnosed metastases by year. (B) Time to metastasis in years from primary diagnosis.

metastasis and survival was examined using the log-rank test, which was applied to the model. The R function 'coxph' from the package 'survival' was used for the analysis (28). Kaplan-Meier curves were analyzed using the function 'survfit' and were visualized using the R package 'ggfortify' $(29,30)$. To compare the estimated survival of the present study with already published data the Surveillance, Epidemiology and End Results (SEER) database (2) was used for the Caucasian population.

\section{Results}

Patient characteristics. The number of newly diagnosed cases of metastasis was demonstrated to consistently increase over time in the study cohort (Fig. 1A). A total of 647 out of 2,026 patients $(31.9 \%)$ were indicated to develop metastasis, and $219(10.8 \%)$ patients presented with metastasis at the time of diagnosis. A total of 428 (21.1\%) patients developed metastasis during the study period, and of these, 119 patients (5.9\%) developed metastases within the first 6 months following treatment and were subsequently excluded from the case-control study. Therefore, a total of 309 patients with melanoma (15.3\%), for which metastases were diagnosed at $\geq 6$ months after the beginning of treatment, were included in the analysis. Of these, 278 patients were matched with controls by age and sex, including 164 female (59.0\%) and 114 male $(41.0 \%)$ patients. The mean age was $61.8 \pm 14.9$ years for female and 61.1 \pm 13.6 years for male patients (Mann-Whitney test, $\mathrm{P}=0.340)$. The majority of the patients $(\mathrm{n}=192$ or $66.7 \%)$ developed metastasis within the first two years following surgery (Fig. 1B).

Risk factors associated with melanoma metastasis. The distribution of risk factors within the case and control groups, and the associations between clinicopathological features and metastasis are presented in Table I. Thick melanomas were observed in the case and control groups, although the mean tumor thickness at diagnosis was higher in patients with metastasis compared with that in patients without metastasis (5.21 vs. $4.02 \mathrm{~mm}$, respectively; Mann-Whitney test, $\mathrm{P}=0.012$ ). The likelihood of developing metastasis for patients with melanoma Breslow thickness $>4.00 \mathrm{~mm}$ and those with lower Breslow thickness was also compared, as $4.00 \mathrm{~mm}$ is the threshold used for separating patients with melanoma T stages IA-IIC and stages IIIA-IV; the likelihood of metastasis was significantly higher in patients with melanoma Breslow thickness $>4.00 \mathrm{~mm}$ [odds ratio (OR), 1.59; 95\% CI, 1.06-2.38; $\mathrm{P}=0.030$ ]. Pairwise comparisons among four intervals of Breslow thickness indicated that patients with melanomas with Breslow thickness 2.01-4.00 and $>4 \mathrm{~mm}$ were more likely to develop metastasis compared with patients with melanomas of $1.01-2.00 \mathrm{~mm}\left(\mathrm{P}=0.009\right.$ and $\mathrm{P}=4.94 \times 10^{-4}$, respectively; Table SI). The presence of ulceration significantly increased the risk of metastasis (OR, 1.66; 95\% CI, 1.07-2.59; $\mathrm{P}=0.033$ ), and the absence of pigment from melanoma tissue was also associated with the likelihood of metastasis (OR, 2.14; 95\% CI, 1.10-4.19; $\mathrm{P}=0.035$; Table I).

Within the initial cohort of 309 individuals, which were paired with controls only by the year of initial diagnosis and the time of follow-up, male sex also appeared to be a significant risk factor (OR, 1.53; 95\% CI, 1.10-2.12; P=0.013). In addition, the anatomical localization of melanoma was associated with the development of metastasis ( $\mathrm{P}=0.034$; Table SII). To explore this further, the differences in melanoma features between female and male patients were examined. The anatomical localization of melanoma was the only characteristic that was indicated to be significantly different for male and female patients (Table II). Localizations differed for both sexes among the patients with metastasis $(\mathrm{P}=0.010)$ as well as among the control subjects without metastasis $(\mathrm{P}=0.003$; Table SIII). Relative to those on limbs, male patients presented with more cases of melanoma on their trunk, hands and feet, as well as on the head and neck compared with female patients (Table III). Melanoma localization on the trunk had significantly different frequencies for males and females when individuals were stratified into groups by metastatic status, 
Table I. Risk factors for melanoma metastasis (sex- and age-matched dataset, $\mathrm{n}=278$ ).

\begin{tabular}{|c|c|c|c|c|c|c|}
\hline \multirow[b]{2}{*}{ Risk factor } & \multicolumn{2}{|c|}{$\begin{array}{l}\text { Patients with } \\
\text { metastasis }\end{array}$} & \multicolumn{2}{|c|}{$\begin{array}{l}\text { Patients without } \\
\text { metastasis }\end{array}$} & \multirow[b]{2}{*}{ OR $(95 \% \mathrm{CI})$} & \multirow[b]{2}{*}{ P-value ${ }^{a}$} \\
\hline & $\mathrm{N}$ & $\%$ & $\mathrm{~N}$ & $\%$ & & \\
\hline \multicolumn{7}{|l|}{ Tumor localization } \\
\hline Head and neck & 28 & 10.1 & 41 & 14.7 & & 0.400 \\
\hline Limbs & 113 & 40.6 & 104 & 37.4 & & \\
\hline Trunk & 117 & 42.1 & 115 & 41.4 & & \\
\hline Hands and feet ${ }^{\mathrm{d}}$ & 20 & 7.2 & 18 & 6.5 & & \\
\hline Total $^{\mathrm{e}}$ & 278 & 100.0 & 278 & 100.0 & & \\
\hline \multicolumn{7}{|l|}{ CM subtype } \\
\hline Superficial spreading melanoma & 15 & 20.8 & 8 & 11.1 & & $0.219^{c}$ \\
\hline Nodular melanoma & 55 & 76.4 & 60 & 83.3 & & \\
\hline Lentigo malignant melanoma & 2 & 2.8 & 4 & 5.6 & & \\
\hline Total $^{\mathrm{e}}$ & 72 & 100.0 & 72 & 100.0 & & \\
\hline \multicolumn{7}{|l|}{ Breslow thickness, mm } \\
\hline Mean \pm SD & \multicolumn{2}{|c|}{$5.21 \pm 6.17$} & \multicolumn{2}{|c|}{$4.02 \pm 4.95$} & & $0.012^{\mathrm{b}}$ \\
\hline Median & \multicolumn{2}{|c|}{4.0} & \multicolumn{2}{|c|}{2.5} & & \\
\hline$\leq 1.0$ & 54 & 25.1 & 55 & 25.5 & & 0.005 \\
\hline $1.0-2.0$ & 23 & 10.7 & 49 & 22.8 & & \\
\hline $2.0-4.0$ & 55 & 25.6 & 50 & 23.3 & & \\
\hline$>4.0$ & 83 & 38.6 & 61 & 28.4 & & \\
\hline Total $^{\mathrm{e}}$ & 215 & 100.0 & 215 & 100.0 & & \\
\hline \multicolumn{7}{|l|}{ Ulceration } \\
\hline Absent & 61 & 37.9 & 81 & 50.3 & $\begin{array}{c}\text { Reference } \\
1.66(1.07-2.59)\end{array}$ & \\
\hline Present & 100 & 62.1 & 80 & 49.7 & & 0.033 \\
\hline Total $^{\mathrm{e}}$ & 161 & 100.0 & 161 & 100.0 & & \\
\hline \multicolumn{7}{|l|}{ Pigment } \\
\hline Present & 195 & 87.4 & 209 & 93.7 & $\begin{array}{c}\text { Reference } \\
2.14(1.10-4.19)\end{array}$ & \\
\hline Absent & 28 & 12.6 & 14 & 6.3 & & 0.035 \\
\hline Total $^{\mathrm{e}}$ & 223 & 100.0 & 223 & 100.0 & & \\
\hline \multicolumn{7}{|l|}{ Predominant cell type in the lesion } \\
\hline Epithelial & 121 & & 67.6 & 118 & 65.9 & 0.139 \\
\hline Spindle & 21 & & 11.7 & 33 & 18.4 & \\
\hline Mixed & 37 & & 20.7 & 28 & 15.7 & \\
\hline Total $^{\mathrm{e}}$ & 179 & & 100.0 & 179 & 100.0 & \\
\hline \multicolumn{7}{|l|}{ BMI } \\
\hline Mean \pm SD & \multicolumn{2}{|c|}{$28.64 \pm 5.56$} & \multicolumn{2}{|c|}{$28.20 \pm 5.93$} & & $0.462^{\mathrm{b}}$ \\
\hline Median & \multicolumn{2}{|c|}{27.5} & \multicolumn{2}{|c|}{27.8} & & \\
\hline $18.61-25.00$ & 40 & & 27.0 & 44 & 29.7 & 0.869 \\
\hline $25.01-30.00$ & 57 & & 38.5 & 54 & 36.5 & \\
\hline$>30.01$ & 51 & & 34.5 & 50 & 33.8 & \\
\hline Total $^{\mathrm{e}}$ & 148 & & 100.0 & 148 & 100.0 & \\
\hline
\end{tabular}

${ }^{\text {aP }}$-values were obtained by the $\chi^{2}$ test unless indicated otherwise. ${ }^{b}$ Mann-Whitney test. ${ }^{c}$ Fisher's exact test. ${ }^{\mathrm{d}}$ Acral lentiginous melanomas were

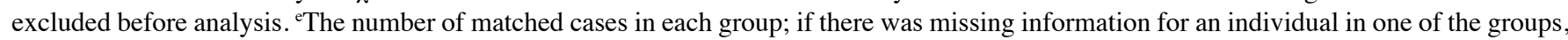
the corresponding case-control pair was excluded from the analysis. OR and 95\% CI are presented for predictors with two categories. If a predictor had more than two categories, then the overall significance of a predictor was evaluated first. If the obtained P-value was significant (e.g., Breslow thickness), pairwise comparisons were performed, and odds ratios were calculated for combinations of two categories (Table SI).

and it differed by sex for patients without and with metastasis (OR, 2.82; 95\% CI, 1.61-4.96; P=3.26x10-4; and OR, 2.47; 95\% CI, 1.43-4.25; $\mathrm{P}=1.22 \times 10^{-3}$, respectively; Tables SIV and
SV). The analysis of melanoma features within the female and male cohorts separately demonstrated that tumor Breslow thickness, ulceration and absence of pigment were associated 


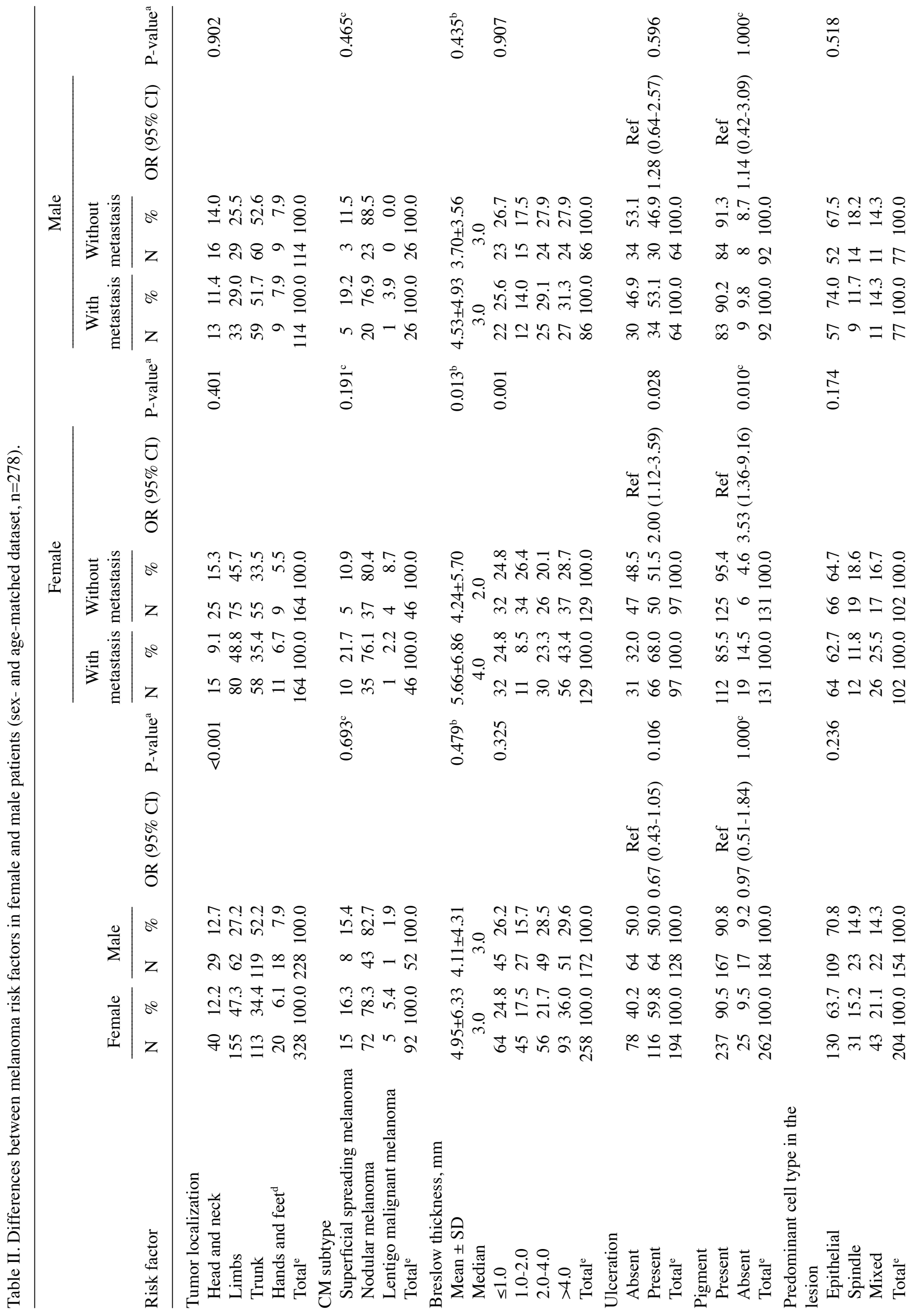


with metastasis in female patients, whereas similar associations were not observed in the male cohort (Table II).

Multivariate models built by stepwise regression demonstrated that the only independently significant prognostic factor for the development of metastasis was tumor ulceration, and it was selected as it significantly improved the multivariate model according to the overall model likelihood and the Akaike Information Criterion (ulceration OR, 1.62; 95\% CI,1.00-2.62; $\mathrm{P}=0.051)$. Age and sex were incorporated in this model by the matching of cases and controls.

Patient survival. The survival of patients exhibiting primary melanoma differed significantly from those who developed metastasis [hazard ratio (HR), 3.50; 95\% CI, 2.72-4.51; $\mathrm{P}<2.00 \times 10^{-16}$; Fig. 2A]. Improved survival was also observed in female compared with male patients (HR, 1.44; 95\% CI, 1.14-1.81; $\left.\mathrm{P}=1.94 \times 10^{-3}\right)$. However, this difference was only observed in females without metastasis (HR, 1.86; 95\% CI, 1.20-2.88; $\left.\mathrm{P}=5.04 \times 10^{-3}\right)$, and was not observed once metastasis had developed (HR, 1.05; 95\% CI, 0.80-1.37; P=0.744; Fig. 2B-D). The comparison of patients' survival in the present study with the survival reported in the SEER data base (2) demonstrated that the 5-year survival after the initial diagnosis was $61.1 \%$ in the cohort of the present study compared with $91.6 \%$ for the Caucasian population in the SEER database. These differences in survival were observed both for localized disease (controls without metastasis; $\mathrm{T}$ stages IA-IIC) and for melanoma with metastasis (cases; T stages IIIA-IV). The survival rates were $41.9 \%$ (controls) and $80.7 \%$ (cases) in the present study compared with 65 and $98.3 \%$ in the SEER database for the respective groups (Table IV) (2).

Time until metastasis since primary diagnosis. The time until metastasis was diagnosed was also considered in the current study. The results demonstrated that increased age was associated with shorter time until metastasis (incident rate ratio (IRR), 6.85; 95\% CI, 2.43-19.30; $\mathrm{P}=2.78 \times 10^{-4}$ ) (Fig. 3A). In addition, ulceration indicated a borderline significant association with shorter time until metastasis (IRR=1.33, 95\% CI=0.98-1.80; $\mathrm{P}=0.064$; Fig. 3B). None of the remaining factors exhibited an association with shorter time until metastasis, including tumor Breslow thickness and sex $(\mathrm{P}=0.997$ and $\mathrm{P}=0.588$, respectively; Fig. 3C and D).

\section{Discussion}

The present study revealed an ascending trend for the number of melanomas that progress towards metastasis from 1988-2015. This trend was consistent with the observations of other studies, where a decline in late-stage melanomas was not observed, and a decrease in the mortality caused by melanoma was also not observed (1). The results of the current study indicated that tumor ulceration exhibited the strongest association with melanoma metastasis. Furthermore, tumor ulceration was indicated to be the only independently significant prognostic factor for the development of metastasis in the multivariate model. Tumor ulceration has been previously reported to be a prognostic factor for melanoma $(17,18,21,22)$. In the present study, ulceration was also nominally associated with a shorter 
Table III. Pairwise comparisons of the frequencies of tumor localization for female and male patients (sex- and age-matched dataset, $n=278$ ).

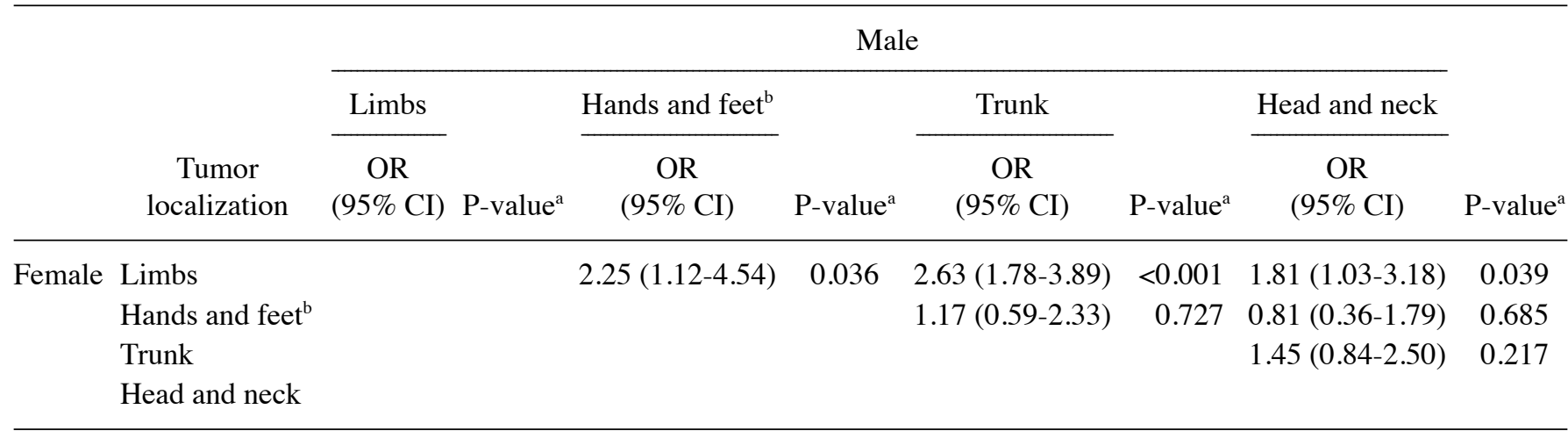

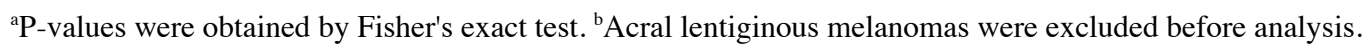
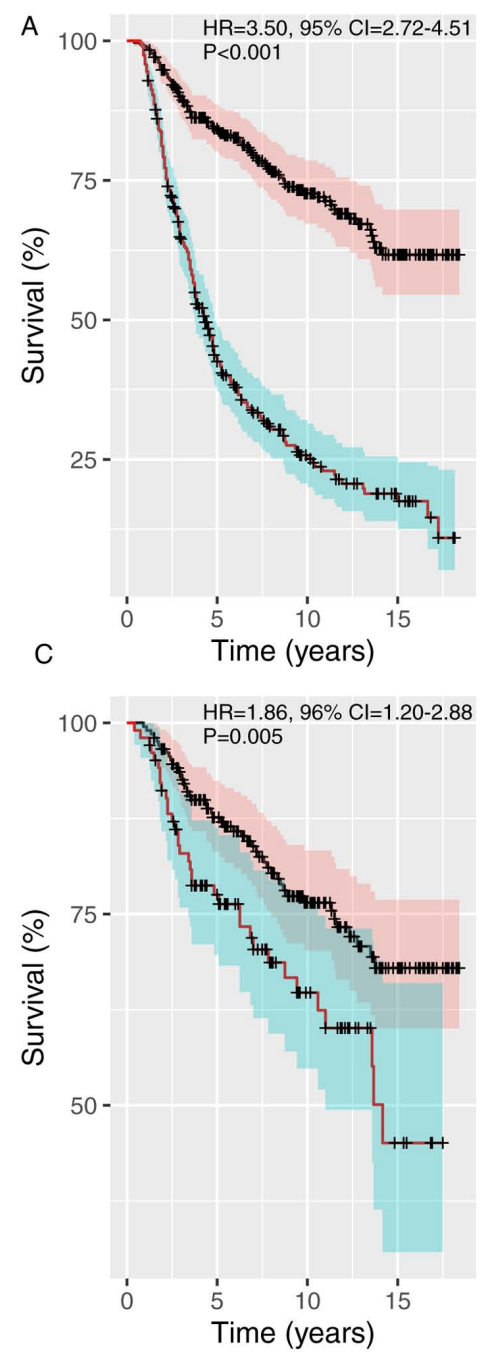
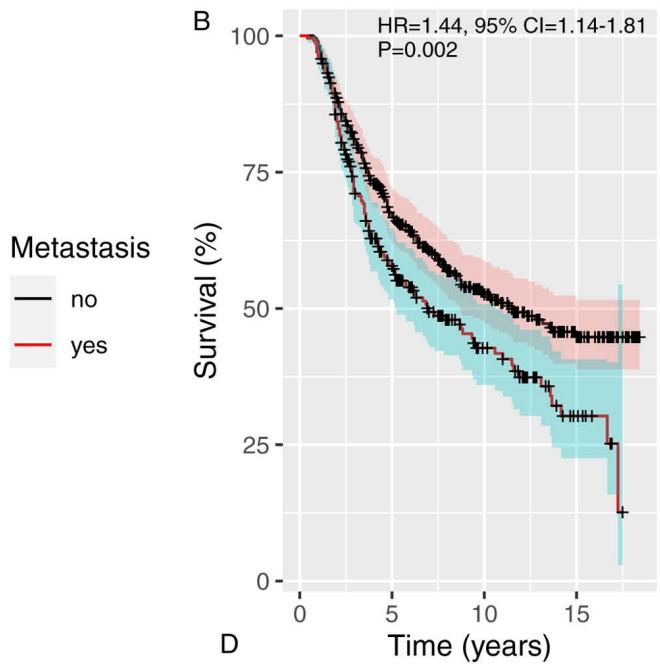

Survival

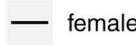

- male

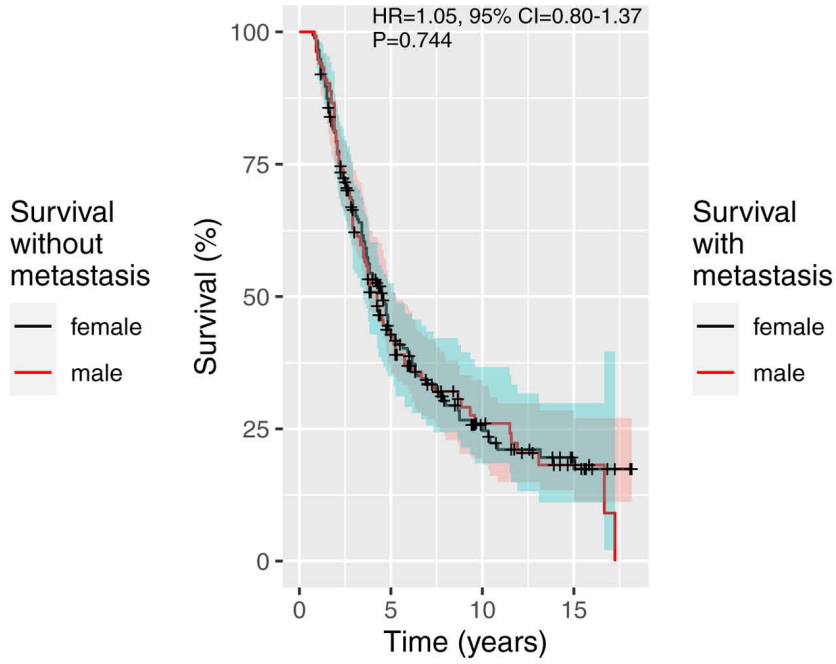

Figure 2. Kaplan-Meier curves of differences in survival based on clinicopathological characteristics. (A-D) Kaplan-Meier curves of (A) patients with primary melanoma (T stage IA-IIC) compared with those with metastasis (T stage IIIA-IV), (B) female and male patients irrespective of the presence of metastasis, (C) female and male patients without metastasis and (D) female and male patients with metastasis.

time until the development of metastasis. Tumor Breslow thickness was another factor that exhibited a strong association with melanoma metastasis; this measurement is an important hallmark of melanoma progression, and it is recognized as one of the main prognostic factors on which the current clinical staging of melanoma is based $(10,11)$. Patients in the cohort used in the present study exhibited thicker melanomas with a median Breslow thickness of $3.00 \mathrm{~mm}(4.00 \mathrm{~mm}$ in patients 
Table IV. Patient 5-year survival rates in the local cohort and the SEER database (2).

5-year survival rate, $\%$

Stage

Local cohort

SEER database

All melanomas

61.1

91.6

Localized disease (T stage IA-IIC)

80.7

98.3

Metastasis (regional and distant; T stage IIIA-IV)

41.9

65.0

SEER, Surveillance, Epidemiology and End Results.
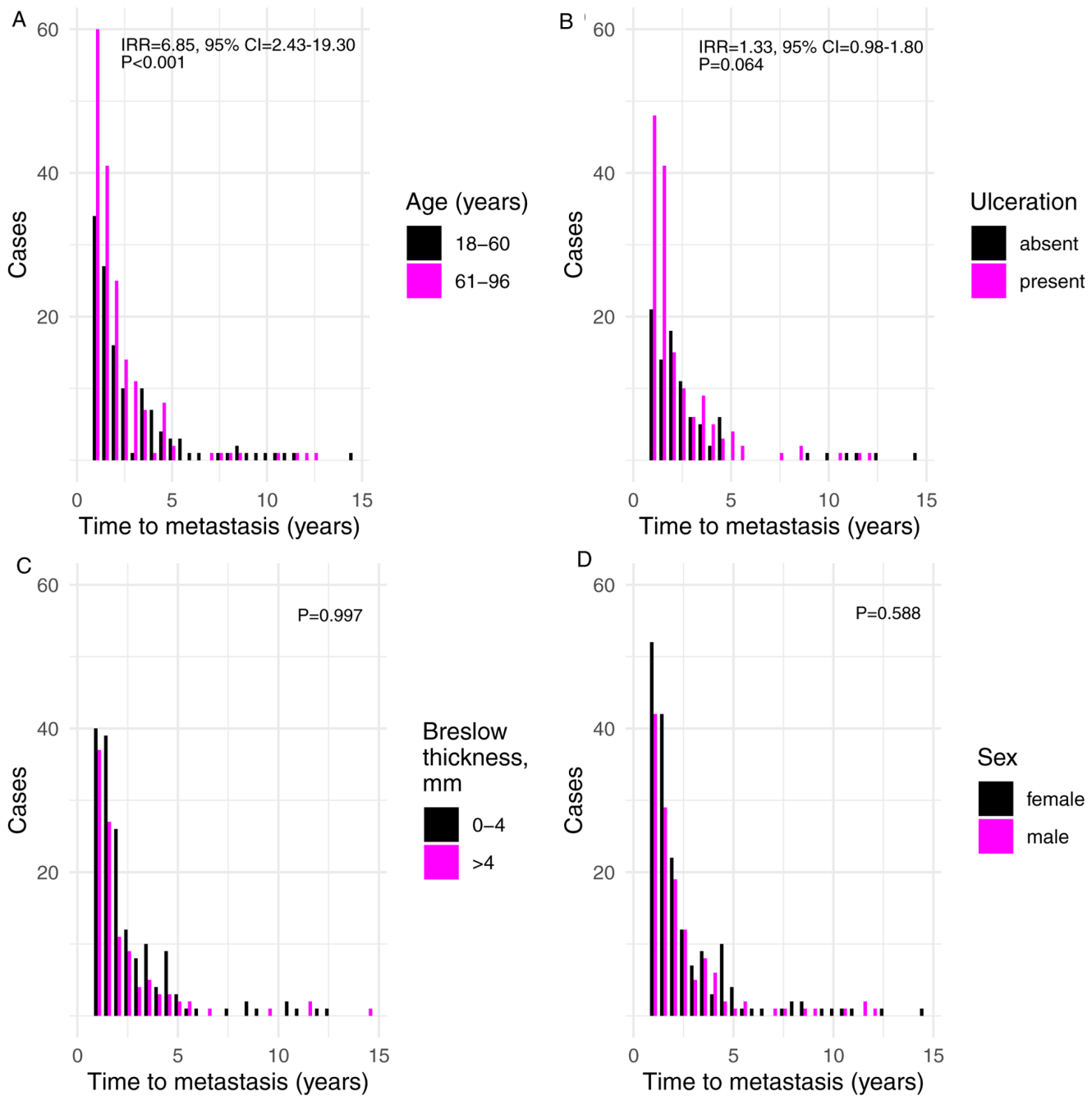

Figure 3. Associations between time to metastasis in years and various characteristics of melanoma. (A-D) Time to metastasis in years by (A) age at the time of diagnosis, (B) presence of ulceration, (C) logarithm of Breslow thickness (analyzed as a continuous variable) and (D) sex.

with metastasis and $2.50 \mathrm{~mm}$ in those without) compared with other studies reporting a median thickness of $0.62 \mathrm{~mm}$ and a steady decrease of this metric $(6,31)$. However, the percentage of patients with primary melanoma who developed metastasis was only slightly higher in the current study compared with the previous literature at $31.9 \%$ vs. $30.0 \%$, respectively $(8,9)$. In addition, Breslow thickness exhibited no impact on the time when metastasis was diagnosed within the present study. Tumor thickness may be a proxy of the stage of primary tumor advancement, and the spreading of melanoma may be independent of the thickness of primary tumor at the time of diagnosis. This may mean that tumor Breslow thickness is not the main determinant of the speed with which metastasis develops, and that other mechanisms are responsible for this spread. Alternatively, the lack of association between Breslow thickness and the time of metastasis development may be due to the different effects of the initial Breslow thickness on early and late metastasis. Of note, the survival rate in the present cohort was noticeably lower compared with that reported in the literature (2). This might be explained by the delays in seeking 
medical assistance and by the availability of state-of-the-art treatment options during the study period (1998-2015) in Latvia. In addition patients' age and mortality from other diseases may have had an influence on this discrepancy, especially because the difference was similar for patients with metastasis and patients without metastasis (localized disease). This observation emphasizes the requirement for identifying additional patient and melanoma characteristics that may be associated with disease progression.

Ulceration, tumor Breslow thickness and the absence of pigment in melanoma tissues are known prognostic factors for melanoma $(17,21)$ and were associated with metastasis in the cohort used in the present study. These features were associated with the development of melanoma metastasis in female patients, whereas similar associations were not observed in the male cohort. However, male sex appeared to be a significant risk factor for the development of melanoma metastasis. In 1969 , Clark et al (32) observed that melanomas were more aggressive in male patients compared with those in female patients. Numerous studies have consistently indicated sex to be an independent prognostic factor for the development of melanoma even after the adjustment for age, Breslow thickness, histological subtype and body site (33-36), ulceration (36-38), vascular invasion (39), mitotic rate (38) and sentinel lymph node positivity $(34,36,40)$. A biological basis for this advantage in female survival has been suggested $(34,35)$. A number of factors have been hypothesized to contribute to the increased female patient survival, including sex-linked physiological differences in skin, sex hormone levels, pregnancy, use of oral contraceptives and hormone replacement therapy [reviewed in (41)] and the presence of oxidative stress (42). However, the precise biological mechanism underlying this phenomenon remains to be determined. In the current study, no significant differences between male and female patients in terms of age, tumor Breslow thickness, histological subtype, pigment and ulceration were observed. No discrepancies in these factors were observed when male and female patients were compared separately within groups with and without metastasis. However, it was demonstrated that melanoma localization differed among sexes. A previous study has reported similar results, revealing that among various risk factors, only localization is not similarly distributed for both sexes (5). In the present study and in the aforementioned studies, female patients exhibited more melanomas on the limbs, whereas male patients had a number of melanomas on the trunk (5). According to previous studies, melanomas on the trunk exhibit a worse prognosis compared with melanomas on the extremities (43-45). Age is another factor that is often associated with a poor prognosis, especially in male patients (46). This was not confirmed in the current study, although it was indicated that advanced age was associated with a shorter time until the onset of metastasis in both sexes.

A major limitation of the current study was acquiring data from a large referral center, which may not fully represent the Latvian population. However, REUHLOC is the main oncological hospital in the country, where the majority of patients with melanoma are treated. A similar approach to data collection has been used previously (47). In addition, patients were not classified according to melanoma sub-stages. The rationale behind this decision was as follows. It is important to utilize as much of the available information about patients and tumors as possible to improve the prediction of metastases. Each conversion of a continuous feature, such as Breslow thickness, into a discrete characteristic is associated with loss of information and reduces the statistical power of models where this feature is included. The consequences of collapsing several features into one coarser trait are similar. Thus, it is preferable to consider multiple features simultaneously in a multivariate model. Using disease stages may be beneficial if there were numerous outliers in the data. However, such trends were not observed in the present study. The type of treatment received by a patient was not incorporated into statistical models and is a limitation of the present study. This was done as during the study period no novel treatment options were available and all patients in the cohort in the present study received standard treatments: Patients with stage I and II disease were put under observation, stage III melanoma patients mostly received interferon alpha (IFN- $\alpha$ ) and for stage IV patients the main treatment option was chemotherapy with dacarbazine.

In conclusion, the present study demonstrated that the main features associated with the speed of melanoma progression and the development of metastasis in Latvia, despite the lower 5-year survival rates, are similar to those reported previously and include tumor ulceration, absence of pigment in melanoma and tumor Breslow thickness, although the latter is not associated with the time at which metastasis is diagnosed. The present study also indicated that an additional feature associated with melanoma progression is male sex.

\section{Acknowledgements}

The authors would like to thank Ms. Anna Azaryan (Vienna University, Austria) for critical reading and advice regarding the manuscript and Ms. Irina Verhovcova (Latvian Biomedical Research and Study Centre, Riga, Latvia) for technical assistance in the manuscript preparation.

\section{Funding}

This work was supported by The European Regional Development Fund (project no. 1.1.1.1/18/A/099).

\section{Availability of data and materials}

The datasets used and/or analyzed in the present study are available from the corresponding author upon a reasonable request.

\section{Authors' contributions}

DP designed the study, interpreted the data and was a major contributor in writing the manuscript. DR performed statistical analyses, interpreted the data and was a major contributor in writing the manuscript. IC conceived the study and interpreted the data. KA, EK and AO acquired the data. All authors read, edited and approved the final manuscript.

\section{Ethics approval and consent to participate}

The Research Ethics Committee of the Institute of Cardiology and Regenerative Medicine of University of Latvia approved the study protocol. 


\section{Patient consent for publication}

Not applicable.

\section{Competing interests}

The authors declare that they have no competing interests.

\section{References}

1. Apalla Z, Lallas A, Sotiriou E, Lazaridou E and Ioannides D Epidemiological trends in skin cancer. Dermatol Pract Concept 7 : 1-6, 2017.

2. SEER*Explorer: An interactive website for SEER cancer statistics. Surveillance Research Program, National Cancer Institute. https://seer.cancer.gov/explorer/. Accessed June 26, 2020.

3. Lasithiotakis KG, Leiter U, Gorkievicz R, Eigentler T, Breuninger H, Metzler G, Strobel W and Garbe C: The incidence and mortality of cutaneous melanoma in southern Germany: Trends by anatomic site and pathologic characteristics, 1976 to 2003. Cancer 107: 1331-1339, 2006.

4. Stang A, Pukkala E, Sankila R, Söderman B and Hakulinen T: Time trend analysis of the skin melanoma incidence of Finland from 1953 through 2003 including 16,414 cases. Int J Cancer 119: 380-384, 2006.

5. Azarjana K, Ozola A, Ruklisa D, Cema I, Rivosh A, Azaryan A and Pjanova D: Melanoma epidemiology, prognosis and trends in Latvia. J Eur Acad Dermatol Venereol 27: 1352-1359, 2013.

6. Shaikh WR, Dusza SW, Weinstock MA, Oliveria SA, Geller AC and Halpern AC: Melanoma thickness and survival trends in the United States, 1989-2009. J Natl Cancer Inst 108: djv294, 2015.

7. Whiteman DC, Green AC and Olsen CM: The growing burden of invasive melanoma: Projections of incidence rates and numbers of new cases in six susceptible populations through 2031. J Invest Dermatol 136: 1161-1171, 2016.

8. Essner R, Lee JH, Wanek LA, Itakura $\mathrm{H}$ and Morton DL: Contemporary surgical treatment of advanced-stage melanoma. Arch Surg 139: 961-967, 2004.

9. Oliaro A, Filosso PL, Bruna MC, Mossetti C and Ruffini E: Pulmonary metastasectomy for melanoma. J Thorac Oncol 5 (6 Suppl 2): S187-S191, 2010

10. Balch CM, Gershenwald JE, Soong SJ, Thompson JF, Atkins MB Byrd DR, Buzaid AC, Cochran AJ, Coit DG, Ding S, et al: Final version of 2009 AJCC melanoma staging and classification. J Clin Oncol 27: 6199-6206, 2009.

11. Gershenwald JE, Scolyer RA, Hess KR, Sondak VK, Long GV, Ross MI, Lazar AJ, Faries MB, Kirkwood JM, McArthur GA, et al: Melanoma staging: Evidence-based changes in the American joint committee on cancer eighth edition cancer staging manual. CA Cancer J Clin 67: 472-492, 2017.

12. Sullivan RJ and Flaherty KT: Resistance to BRAF-targeted therapy in melanoma. Eur J Cancer 49: 1297-1304, 2013.

13. Rizos H, Menzies AM, Pupo GM, Carlino MS, Fung C, Hyman J, Haydu LE, Mijatov B, Becker TM, Boyd SC, et al: BRAF inhibitor resistance mechanisms in metastatic melanoma: Spectrum and clinical impact. Clin Cancer Res 20: 1965-1977, 2014.

14. Vilgelm AE, Johnson DB and Richmond A: Combinatorial approach to cancer immunotherapy: Strength in numbers. J Leukoc Biol 100: 275-290, 2016.

15. Bhandaru M and Rotte A: Monoclonal antibodies for the treatment of melanoma: Present and future strategies. Methods Mol Biol 1904: 83-108, 2019.

16. Weiss SA, Wolchok JD and Sznol M: Immunotherapy of melanoma: Facts and hopes. Clin Cancer Res 25: 5191-5201, 2019.

17. Homsi J, Kashani-Sabet M, Messina JL and Daud A: Cutaneous melanoma: Prognostic factors. Cancer Control 12: 223-229, 2005.

18. In 't Hout FE, Haydu LE, Murali R, Bonenkamp JJ, Thompson JF and Scolyer RA: Prognostic importance of the extent of ulceration in patients with clinically localized cutaneous melanoma. Ann Surg 255: 1165-1170, 2012.

19. Han D, Zager JS, Shyr Y, Chen H, Berry LD, Iyengar S, Djulbegovic M, Weber JL, Marzban SS, Sondak VK, et al: Clinicopathologic predictors of sentinel lymph node metastasis in thin melanoma. J Clin Oncol 31: 4387-4393, 2013.
20. Dummer R, Hauschild A, Lindenblatt N, Pentheroudakis G and Keilholz U; ESMO Guidelines Committee: Cutaneous melanoma: ESMO clinical practice guidelines for diagnosis, treatment and follow-up. Ann Oncol 26 (Suppl 5): v126-v132, 2015.

21. Elder DE: Melanoma progression. Pathology 48: 147-154, 2016.

22. Portelli F, Galli F, Cattaneo L, Cossa M, De Giorgi V, Forte G, Fraternali Orcioni G, Gianatti A, Indini A, Labianca A, et al: The prognostic impact of the extent of ulceration in clinical stage I-II melanoma patients: A multicenter study of the Italian melanoma intergroup (IMI). Br J Dermatol, Apr 13, 2020 (Epub ahead of print).

23. Balch CM, Soong SJ, Gershenwald JE, Thompson JF, Coit DG, Atkins MB, Ding S, Cochran AJ, Eggermont AM, Flaherty KT, et al: Age as a prognostic factor in patients with localized melanoma and regional metastases. Ann Surg Oncol 20: 3961-3968, 2013.

24. Brauer JA, Wriston CC, Troxel AB, Elenitsas R, Shin DB, Guerry DP and Ming ME: Characteristics associated with early and late melanoma metastases. Cancer 116: 415-423, 2010.

25. Messeguer F, Agustí-Mejías A, Traves V, Requena C, Alegre V, Guillén C, Oliver V and Nagore E: Mitotic rate and subcutaneous involvement are prognostic factors for survival after recurrence in patients with only locoregional skin metastasis as the first site of recurrence from cutaneous melanoma. J Eur Acad Dermatol Venereol 27: 436-441, 2013.

26. R Core Team. R: A language and environment for statistical computing. Version 3.6.3. R Foundation for Statistical Computing, Vienna, 2012. http://www.R-project.org/.

27. Venables WN and Ripley BD: Modern applied statistics with S. Fourth edition. Springer, New York, NY, 2002

28. Therneau TM: A package for survival analysis in S. Version 2.38 , 2015. https://CRAN.R-project.org/package=survival.

29. Tang Y, Horikoshi M and Li W: ggfortify: Unified interface to visualize statistical result of popular $R$ packages. The $R$ Journal 8: 474-485, 2016.

30. Horikoshi M and Tang Y: ggfortify: Data visualization tools for statistical analysis results. https://CRAN.R-project.org/ package $=$ ggfortify

31. Davies JR, Randerson-Moor J, Kukalizch K, Harland M, Kumar R, Madhusudan S, Nagore E, Hansson J, Höiom V, Ghiorzo P, et al: Inherited variants in the MC1R gene and survival from cutaneous melanoma: A BioGenoMEL study. Pigment Cell Melanoma Res 25: 384-394, 2012.

32. Clark WH Jr, From L, Bernardino EA and Mihm MC: The histogenesis and biologic behavior of primary human malignant melanomas of the skin. Cancer Res 29: 705-727, 1969.

33. Downing A, Newton-Bishop JA and Forman D: Recent trends in cutaneous malignant melanoma in the Yorkshire region of England; incidence, mortality and survival in relation to stage of disease, 1993-2003. Br J Cancer 95: 91-95, 2006.

34. Lasithiotakis K, Leiter U, Meier F, Eigentler T, Metzler G, Moehrle M, Breuninger $\mathrm{H}$ and Garbe $\mathrm{C}$ : Age and gender are significant independent predictors of survival in primary cutaneous melanoma. Cancer 112: 1795-1804, 2008.

35. de Vries E, Nijsten TE, Visser O, Bastiaannet E, van Hattem S, Janssen-Heijnen ML and Coebergh JW: Superior survival of females among 10538 Dutch melanoma patients is independent of Breslow thickness, histologic type and tumor site. Ann Oncol 19: 583-589, 2008.

36. Mays MP, Martin RC, Burton A, Ginter B, Edwards MJ, Reintgen DS, Ross MI, Urist MM, Stromberg AJ, McMasters KM and Scoggins CR: Should all patients with melanoma between 1 and $2 \mathrm{~mm}$ Breslow thickness undergo sentinel lymph node biopsy? Cancer 116: 1535-1544, 2010.

37. Balch CM, Soong SJ, Gershenwald JE, Thompson JF, Reintgen DS, Cascinelli N,Urist M, McMasters KM, Ross MI, Kirkwood JM, et al: Prognostic factors analysis of 17,600 melanoma patients: Validation of the American joint committee on cancer melanoma staging system. J Clin Oncol 19: 3622-3634, 2001.

38. Azzola MF, Shaw HM, Thompson JF, Soong SJ, Scolyer RA, Watson GF, Colman MH and Zhang Y: Tumor mitotic rate is a more powerful prognostic indicator than ulceration in patients with primary cutaneous melanoma: An analysis of 3661 patients from a single center. Cancer 97: 1488-1498, 2003.

39. Nagore E, Oliver V, Botella-Estrada R, Moreno-Picot S, Insa A and Fortea JM: Prognostic factors in localized invasive cutaneous melanoma: High value of mitotic rate, vascular invasion and microscopic satellitosis. Melanoma Res 15: 169-177, 2005.

40. Scoggins CR, Ross MI, Reintgen DS, Noyes RD, Goydos JS, Beitsch PD, Urist MM, Ariyan S, Sussman JJ, Edwards MJ, et al: Gender-related differences in outcome for melanoma patients. Ann Surg 243: 693-698, 2006. 
41. Roh MR, Eliades P, Gupta S, Grant-Kels JM and Tsao H: Cutaneous melanoma in women. Int J Womens Dermatol 3 (Suppl 1): S11-S15, 2017.

42. Joosse A, De Vries E, Van Eijck CH, Eggermont AM, Nijsten T and Coebergh JW: Reactive oxygen species and melanoma: An explanation for gender differences in survival? Pigment Cell Melanoma Res 23: 352-364, 2010.

43. Leiter U, Meier F, Schittek B and Garbe C: The natural course of cutaneous melanoma. J Surg Oncol 86: 172-178, 2004.

44. Callender GG, Egger ME, Burton AL, Scoggins CR, Ross MI, Stromberg AJ, Hagendoorn L, Martin RC II and McMasters KM: Prognostic implications of anatomic location of primary cutaneous melanoma of $1 \mathrm{~mm}$ or thicker. Am J Surg 202: 659-665, 2011.
45. Gordon D, Smedby KE, Schultz I, Olsson H, Ingvar C, Hansson J and Gillgren P: Sentinel node location in trunk and extremity melanomas: Uncommon or multiple lymph drainage does not affect survival. Ann Surg Oncol 21: 3386-3394, 2014.

46. Lotz M, Budden T, Furney SJ and Virós A: Molecular subtype, biological sex and age shape melanoma tumour evolution. Br J Dermatol, Apr 13, 2020 (Online ahead of print).

47. Buljan M, Rajacić N, Vurnek Zivković M, Blajić I, Kusić Z and Situm M: Epidemiological data on melanoma from the referral centre in croatia (2002-2007). Coll Antropol 32 (Suppl 2): S47-S51, 2008

(i) $\Theta$ This work is licensed under a Creative Commons Attribution-NonCommercial-NoDerivatives 4.0 International (CC BY-NC-ND 4.0) License. 